\title{
Avaliação da qualidade da madeira comercializada no município de Mossoró, RN - Um estudo de caso
}

\author{
Gabriela Oliveira de Souza ${ }^{1}$, Vinicius Gomes Castro ${ }^{1 \star}$, Pompeu Paes Guimarães ${ }^{1}$, Narjara Walessa \\ Nogueira de Freitas ${ }^{1}$ \\ ${ }^{1}$ Centro de Ciências Agrárias, Universidade federal Rural do Semi-Árido (UFERSA), Mossoró, RN, Brasil.
}

\begin{abstract}
RESUMO O objetivo deste trabalho foi avaliar a qualidade das madeiras comercializadas no município de Mossoró, RN, através de um estudo de caso realizado em empresa de comércio varejista de madeira. Os defeitos foram classificados e quantificados dentro do estoque de madeira de Pinus sp., proveniente do Paraná, e de Manilkara sp., proveniente do Pará. Os defeitos encontrados nestas madeiras da espécie tropical não afetaram a percepção de qualidade dos clientes que procuraram este tipo de produto. Para madeira de Pinus, o defeito mais frequente foi a presença de nós em todas as tábuas avaliadas. Porém, o conjunto de defeitos relacionado aos teores de umidade inadequados das peças representou $63 \%$ do total de defeitos. Para este problema, foram propostas soluções e melhorias através da aplicação das ferramentas de qualidade diagrama de Ishikawa e 5W2H. Foram sugeridas a mudança para o método de secagem artificial realizado pelo fornecedor antes do transporte das peças, assim como, um maior controle da armazenagem do estoque, para se evitar contaminação de biodeteriorantes e reumidificação de peças secas. Sendo que para isso, seria necessário um programa de conscientização e treinamento dos funcionários para identificação e solução de problemas relacionados aos teores de umidades e infestações de fungos.
\end{abstract}

Palavras-chave: controle de qualidade; diagrama de Pareto; diagrama de Ishikawa

\section{Evaluation of wood quality traded in Mossoro/RN county - A study case}

\begin{abstract}
The aim of this work was evaluate the quality of commercialized at the municipality of Mossoró, RN, Brazil, by a case study of a retail store. The defects were classified and quantified considering the Pinus sp., originated from Paraná state, and Manilkara sp. stock, originated from Pará state. There was no tropical hardwood defect that affected clients' perceptions. For Pinus, the most frequent defect was the presence of knots in all evaluated planks. However, the group of defects related to the inadequate moisture content represented $63 \%$ of all defects. For these problems, it was suggested solutions and improvements using Ishikawa diagram and 5W2H tools. The artificial dry method was suggested to be changed by the supplier before the wood transportation, as well, a better control of the warehouse conditions of the retailer to avoid biodeterioration and gain of moisture of already dry pieces. Thus, it was necessary to create an awareness and training program among the staff to capacitate employees to identify and solve problems related to moisture contents and fungi infestation.
\end{abstract}

Keywords: Quality control; Pareto diagram; Ishikawa diagram.

\section{Introdução}

O PIB do setor florestal brasileiro alcançou cifras em torno de R\$ 69 milhões em 2015, um crescimento de 3,0\% em relação ao ano anterior, mesmo em uma época de crise político-econômica interna e da desaceleração da economia chinesa no cenário externo (IBÁ, 2016). Em 2008, a China continuava sendo o principal importador de madeira serrada do mundo participando com 33,16\% de toda a importação mundial, mesmo após uma contínua queda a partir de 2004 (SILVA et al., 2012). O setor pode ser subdividido de acordo com sua cadeia produtiva em função das distinções na utilização da madeira bruta. As três principais classes são: ma- 
deira para bionergia (lenha e carvão), processada mecanicamente (serrados, compensados e laminados) e madeira industrializada (papel e painéis reconstituídos).

Dentre as indústrias de base florestal, cerca de $29 \%$ do faturamento é proveniente da cadeia de madeira processada mecanicamente, que representa $1 \%$ do PIB brasileiro (ABIMCI, 2009), sendo que este setor é, em sua maioria, composto pela produção e comércio de produtos com baixo valor agregado como ripas, caibros, tábuas e similares. Por exemplo, da madeira produzida na região amazônica, $72 \%$ sofre apenas este tipo de processamento antes de ser comercializada (SFB, 2010), sendo que $80 \%$ das madeiras tropicais foram exportadas apenas como madeira serrada em 2011 (LENTINI et al, 2012).

O principal consumidor de produtos serrados é o mercado de construção civil. Da madeira amazônica certificada produzida no Brasil, 77\% foi direcionada para esse setor, sendo que o consumo da região Nordeste correspondeu a aproximadamente 20 mil metros cúbicos no ano de 2011, valor inferior ao apresentado pela região Sul (cerca de 40.000 $\mathrm{m}^{3}$ ) ou apenas pelo estado de São Paulo (cerca de $90.000 \mathrm{~m}^{3}$ ) (LENTINI et al, 2012). Porém a perspectiva do aumento de consumo de madeira serrada na região Nordeste tende a acompanhar o crescimento observado no setor da construção civil. Entre 2013 e 2014, o Nordeste registrou o maior crescimento no período, tanto na geração de empregos, quanto no valor das incorporações, obras e serviços da construção (IBGE, 2014).

Qualidade da madeira é um conceito efêmero, uma vez que deve ser definido com base nos atributos que a fazem valiosa para um determinado uso final. Ou seja, a qualidade da madeira é o valor que a sociedade dá as características da madeira que afetarão suas propriedades. Assim, mesmo que o melhoramento genético ou manejo intensivo possam afetar características da madeira, a qualidade sempre dependerá da recepção do produto no mercado (GARTNER, 2005).

Um programa de qualidade, adequadamente elaborado e executado, pode agregar valor aos produtos de madeira, incrementar as vendas e gerar o desenvolvimento do setor (COLLETTI et al., 2010). Contudo, a qualidade da madeira não pode ser uma definição apenas do empresário, pois na prática, se o cliente recebe a mercadoria conforme seu desejo, não haverá a diferenciação entre os concorrentes (SILVA e SOUSA, 2010).

No presente trabalho foi avaliada a qualidade das madeiras comercializadas no município de Mossoró, RN, com o objetivo de: identificar e avaliar o nível de ocorrência dos defeitos; buscar suas possíveis causas e propor um plano de ação para sua eliminação e/ou minimização do problema.

\section{Material e Métodos}

Foi realizado um estudo de caso em uma empresa especializada no comércio de madeira serrada com três lojas no município de Mossoró, RN. O comércio madeireiro no município ainda é insipiente e, em 2016, contava com 10 empresas trabalhando neste setor. A madeireira estudada é a principal da região e comercializa madeira serrada e seca de espécies tropicais de origem de florestas nativas proveniente do estado do Pará e madeira de Pinus originada no estado do Paraná. A madeira tropical é dividida em duas classes comerciais: madeira de Maçaranduba (Manilkara sp.) e madeira "mista" (agrupamento de madeiras de diversas espécies consideradas de menor valor comercial).

Para avaliar a qualidade da madeira comercializada, foram coletados dados referentes ao teor de umidade (TU), biodeterioração e defeitos da madeira serrada. 


\section{Determinação do teor de umidade}

O levantamento da qualidade da madeira foi restrito às madeiras de Manilkara sp. e Pinus sp., que são os principais produtos comercializados pela empresa. As tábuas recémchegadas na empresa foram medidas, separadas por espécie e organizadas em pilhas com área transversal de aproximadamente 4,5 $\mathrm{m}^{2}$. Cada pilha foi subdividida em três níveis de acordo com sua altura (as pilhas tinham em média 1,5 $\mathrm{m}$ de altura, sendo cada nível apresentou $0,5 \mathrm{~m}$ de altura o que compreendia em média 60 tábuas) e, de cada nível, foram selecionadas aleatoriamente três tábuas, que resultou em nove amostras por pilha. Ao todo, foram avaliadas 3 pilhas para cada espécie. As medições foram realizadas com um medidor elétrico resistivo de umidade de madeira da marca Instrutherm, modelo MUMC-620, em três pontos distintos (um ponto central e dois a $30 \mathrm{~cm}$ de cada extremidade da tábua). Sendo que as tábuas de Pinus sp. apresentavam as dimensões médias de 30 × 2 × $300 \mathrm{~cm}$ e as tábuas de Manilkara sp., 30 x $5 \times 450 \mathrm{~cm}$

A estimativa da umidade de equilíbrio (UE) foi obtida pelo uso da Equação 1, apresentada por Jankowsky (1985).

$$
U E(\%)=\left(\frac{K_{1} K_{2} h}{1+K_{1} K_{2} h}+\frac{K_{2} h}{1-K_{2} h}\right) \times \frac{1800}{W}
$$

Em que: $\mathrm{K}_{1}=4,737+0,04773(\mathrm{~T})-0,00050123(\mathrm{~T})^{2} ; \mathrm{K}_{2}=$ $0,70594+0,001698(\mathrm{~T})-0,000005553(\mathrm{~T})^{2} ; \mathrm{W}=223,374+$ $0,69309(\mathrm{~T})+0,01850(\mathrm{~T})^{2} ; \mathrm{T}=$ temperatura em graus Celsius; $\mathrm{h}=$ umidade relativa $/ 100$

\section{Biodeterioração}

Foram avaliados diferentes tipos de ataques biológicos de acordo com a suscetibilidade de cada tipo de madeira comercializada. Todas as peças recém-chegadas que formaram as pilhas utilizadas para o levantamento do teor de umidade também foram inspecionadas em busca da presença de danos causados por insetos e/ou fungos. A identificação da espécie de insetos causadora da deterioração ocorreu pela análise do tipo de dano.

O grau de infestação de fungos manchadores foi determinado pela análise visual através da escala sugerida por Benko e Highley (1990). De acordo com a aparência descrita na Tabela 1 , foram atribuídas notas de 0 a 3 de acordo com um grau crescente de infestação.

Tabela 1. Escala de infestação de fungos manchadores proposta por Benko-Highley (1990).

Table 1. Stain fungal infestation scale suggested by BenkoHighley (1990).

\begin{tabular}{cc}
\hline Notas & Manchas superficiais \\
\hline 0 & Madeira sem manchas visíveis na superfície \\
1 & $\begin{array}{r}\text { Ligeiramente manchadas: pequenos pontos } \\
\text { individuais com diâmetro máximo de } 2 \mathrm{~mm}\end{array}$ \\
& $\begin{array}{r}\text { Moderadamente manchada: Pelo menos } 1 / 3 \\
\text { da superfície é manchada, ou manchas listra- } \\
\text { das que cobrem metade da peça }\end{array}$ \\
3 & Pesadamente manchada: Mais da metade da \\
& superfície manchada
\end{tabular}

\section{Defeitos naturais da madeira e defeitos de seca-}

\section{gem irregular}

Além da avaliação de presença de ataque de biodeterioradores, as tábuas recém-chegadas também foram avaliadas visualmente sendo contabilizados empenamentos do tipo arqueamento (quando as extremidades da tábua não se encontram no mesmo nível), encurvamento (quando a parte central do comprimento da tábua sofreu empenamento lateral), encanoamento (as bordas longitudinais não se encontram no mesmo nível) e torcimento (empenamento tanto no comprimento quanto na largura da peça); rachaduras de superfície e de topo; e presença de nós vivos e mortos (frequência e tamanho médio). 


\section{Diagrama de Pareto}

Os defeitos encontrados na madeira comercializada foram avaliados com auxílio do diagrama de Pareto, ferramenta que auxilia no processo de tomada de decisão ao indicar os problemas críticos e prioritários para solução.

\section{Diagrama Ishikawa e elaboração de plano de}

\section{ação}

Após a determinação dos defeitos, foi utilizado o diagrama Ishikawa, ou diagrama espinha de peixe, para auxiliar na busca das prováveis causas das anomalias. Este é um diagrama de causa-efeito, em que se explora todas as causas possíveis dos problemas específicos indicados

Uma vez determinado os problemas e suas possíveis causas, foi traçado um plano de ação $(5 \mathrm{~W} 2 \mathrm{H})$ para resolver os problemas priorizados. A ferramenta $5 \mathrm{~W} 2 \mathrm{H}$ envolve a resposta de sete questões: O que será feito (What)?; Quando será feito (When)?; Quem fará (Who)?; Onde será feito (When)?; Por que será feito $($ Why)?; Como será feito (How)?; e Quanto irá custar (How much)?.

\section{Resultados e Discussão}

De acordo com Saraiva et al. (2012), a temperatura média do município de Mossoró durante o período de coleta de dados é de $28^{\circ} \mathrm{C}$ e a umidade relativa do ar varia entre 70 e $80 \%$. Ao utilizar a equação de determinação da umidade de equilíbrio adaptada por Jankowosky (1985), pode-se considerar que peças de madeira com teores de umidade entre 12,95 e $15,87 \%$ estão em equilíbrio. Todas as peças de Manilkara $s p$. apresentaram valores abaixo do limite superior do intervalo de equilíbrio, porém mais da metade das peças de Pinus (56\%) estavam com a umidade superior ao limite (Figura 1).

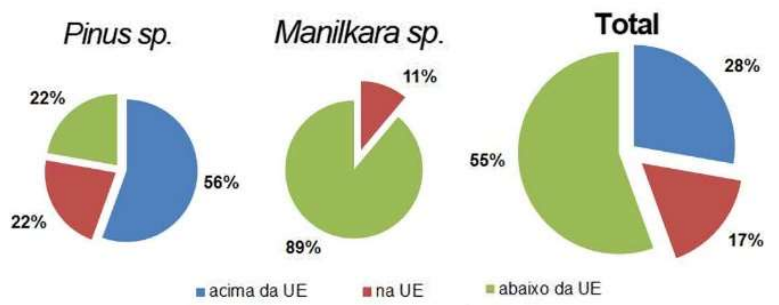

Figura 1. Porcentagens de peças abaixo, acima ou na umidade de equilíbrio.

Figure 1. Percentage of wood pieces below, above or in equilibrium moisture.

A secagem adequada da madeira antes do seu uso final é fundamental por diversos fatores: reduz o peso dos produtos, e assim diminui custos de transporte; a redução das dimensões que ocorrem durante o processo de perda de água passa a acontecer antes do uso da madeira como um produto; a maioria das propriedades mecânicas da madeira aumentam com a secagem; madeira seca é mais apta para receber pregos e parafusos; madeira seca apresenta melhores resultados perante o uso de adesivos ou preservantes químicos; reduz a presença de fungos, manchas e apodrecimento; aumenta as propriedades de isolamento térmico e melhoram o acabamento (FPL, 1999).

O fato da maior parte das tábuas de Pinus apresentar teores de umidade acima do intervalo de equilíbrio foi considerado um problema crítico por ser a provável causa de outros problemas observados neste tipo de material. Embora o fornecedor da madeira tenha garantido que as peças haviam sido secas em seu estado de origem, Paraná, as condições de secagem não considerou as condições climáticas do local de comercialização, Rio Grande do Norte.

Por outro lado, todos os valores médios de umidade das peças de Manilkara foram dentro ou abaixo do intervalo de umidade de equilíbrio. Na secagem artificial, as condições que determinam a umidade de equilíbrio são controladas, tanto a temperatura quanto a umidade relativa do ar (SIMPSON, 1991). É comum que madeiras comercializadas sejam secas 
em estufas a um teor de umidade ligeiramente abaixo da umidade de equilíbrio para antecipar um aumento moderado da umidade durante o processamento e uso (BERGMAN, 2010). Desta forma, o fato da maioria das peças de Manilkara estar abaixo da umidade de equilíbrio esperada (89\%) e nenhuma peça apresentar teor de umidade acima do limite confirmou a informação do fornecedor sobre o uso da secagem artificial antes do transporte da madeira.

Não foram observadas infestações de fungos manchadores em madeiras de Manilkara. Já para a maioria das peças de Pinus (75\%) houve algum grau de ataque deste tipo específico de biodeteriorador (Figura 2).

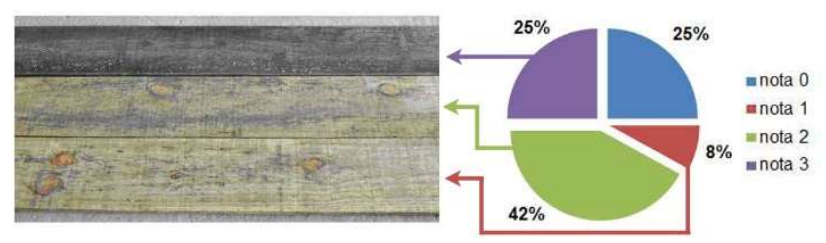

Figura 2. Referência visual de peças de Pinus atacadas por fungos manchadores e porcentagem de infestação.

Figure 2. Visual reference of fungal attacked Pinus wood and infestation percentage.

Fungos manchadores comprometem o aspecto visual da madeira e podem reduzir drasticamente o valor comercial do produto, ao ponto de ser necessário o seu descarte por não atender a qualidade exigida do cliente (HUBBARD et al., 2005). Desta maneira, a alta porcentagem de peças com notas 2 e 3 (67\%) na escala Benko-Highley (1990), ou seja, com mais de $1 / 3$ da superfície coberta com manchas, foi considerada um problema crítico de qualidade. A provável explicação para essa grave infestação foi o método de secagem e as condições de transporte. As tábuas foram transportadas em caminhões fechados e em processo de secagem, gerando um ambiente com alta umidade e temperatura ideal para o desenvolvimento dos fungos.
Em relação aos defeitos da madeira de Manilkara, apenas duas situações foram encontradas: presença de rachaduras de superfície e de rachaduras de topo (Figura 3).

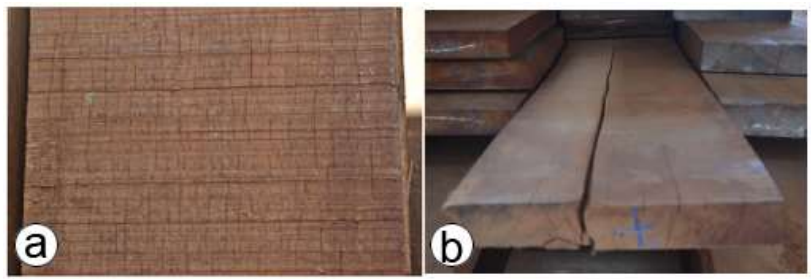

Figura 3. Madeira de Manilkara com: a) rachadura de superfície e b) rachadura de topo.

Figure 3. Manilkara wood presenting: a) surface checks and b) end checks.

As rachaduras da superfície tendem a ocorrer quando há diferença de teores de umidade entre a superfície e o interior da peça durante o processo de secagem. Este defeito é conhecido no comércio local como "madeira rendada" e foi observado em todas as peças de madeira de Manilkara avaliadas, que indica um programa de secagem inadequado. Porém, a presença deste tipo de defeito não causa grandes prejuízos na qualidade da madeira para uso estrutural, por causa das pequenas dimensões (STANGERLIN et al., 2009), e o dano estético não compromete a aceitação do produto pelo mercado consumidor local.

Já as rachaduras de topo são causadas pela secagem rápida das extremidades em comparação com a parte central da peça de madeira. E embora não tenha sido mesurado a extensão das rachaduras, suas presenças foram observadas em diferentes intensidades em todas as tábuas do estoque de Manilkara.

Dentre as peças de Pinus, os defeitos de empenamento encontrados foram enconoamento e torcimento (Figura 4). 


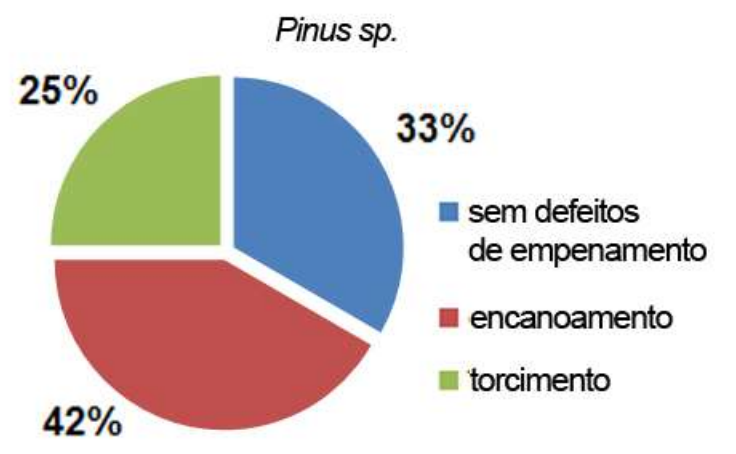

Figura 4. Tipos de empenamentos em peças de Pinus sp. Figure 4. Types of warping in Pinus $s p$. wood pieces.

A maior parte dos defeitos de secagem em peças de Pinus foi do tipo de encanoamento (42\%). A porcentagem para este tipo de defeito foi alta quando comparada às encontradas em outros levantamentos de qualidade com a mesma espécie em estados diferentes (BUSSATTO et al., 2013; GATTO et al., 2004; CADEMARTORI et al., 2012). No caso do torcimento, Gatto et al. (2004) também observaram uma porcentagem de defeito entre 8 e $44 \%$ das peças dependendo da serraria analisada. No caso da madeira comercializada em Mossoró, 25\% das peças apresentaram esse tipo de empenamento, que indica a tendência da espécie a este defeito em caso de secagem inadequada.

Existem diversas razões pelas quais os nós são considerados defeitos. A madeira do nó geralmente possuí densidade acima do resto da madeira, e sua orientação da grã tende a ser perpendicular à região ao seu redor. Como a tendência ao encolhimento é maior no nó do que na madeira, ele pode se soltar ou rachar (HOADLEY, 2000). As tábuas de Pinus avaliadas apresentaram a média de 8,9 nós $/ \mathrm{m}^{2}$, sendo o diâmetro médio dos nós encontrados de $5 \mathrm{~cm}$. A quantidade média do número de nós foi menor do que a encontrada por Gatto et al. (2004) ao avaliar peças secas de Pinus sp. no estado do Rio Grande do Sul, porém, ao contrário do observado em Mossoró, todas as serrarias gaúchas estudadas apresentaram certo número de tábuas sem nós, consideradas de alta qualidade.
Após a fase de levantamento dos defeitos de qualidade da madeira comercializada no estudo de caso e informações sobre a percepção sobre os defeito no produto final comercializado pelo mercado consumidor local, ficou demonstrado que os problemas com maior número de reclamações foram encontradas em peças de Pinus sp.. Assim sendo, apenas o estoque desta espécie foi analisado pelo diagrama de Pareto (Figura 5).

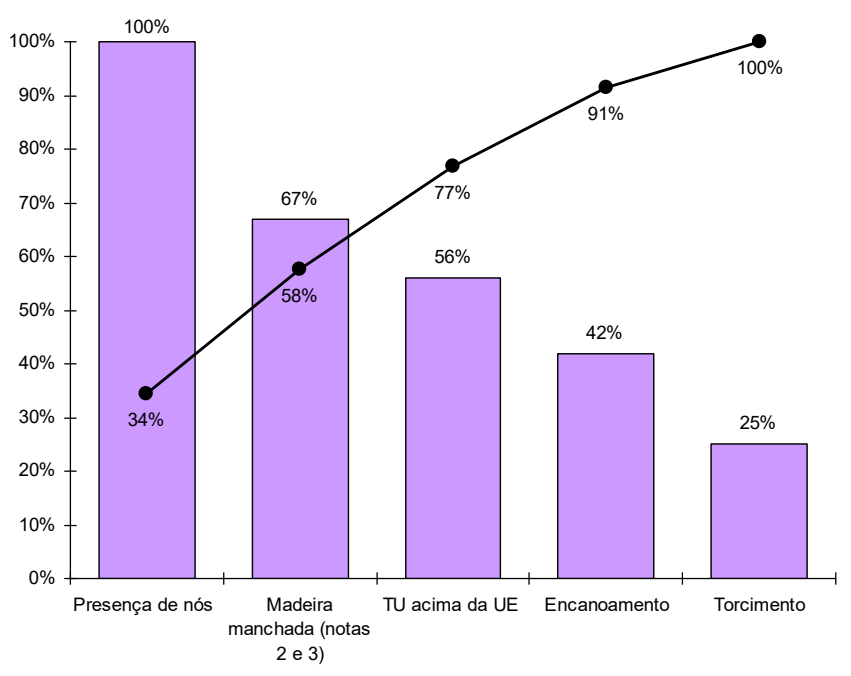

Figura 5. Diagrama de Pareto para os principais defeitos encontrados em peças de Pinus sp.

Figure 5. Pareto chart for main Pinus sp. wood defects.

De acordo com a teoria de Pareto, os principais defeitos são derivados de um número pequeno de causas (LINS, 1993). A presença de nós nas peças representou o defeito de maior incidência nas peças de Pinus comercializadas (34\% do total de defeitos). O segundo e terceiro defeito mais frequente foram a presença de fungos manchadores e peças com teor de umidade acima da umidade de equilíbrio, defeitos estes que estão intimamente correlacionados. Os fungos podem sobreviver, mas não podem crescer em madeira com umidade abaixo de 20\% (KNAEBE, 2002). Os três principais defeitos são responsáveis por $77 \%$ dos problemas encontrados, sendo que se a maior parcela desta porcentagem, que poderia ter sido evitada através de um programa de secagem adequado 
pelo fornecedor, mas que exige a elaboração de um plano de ações corretivas.

O resultado da busca de causas pelo diagrama de Ishikawa (Figura 6) apontou que a falta de controle do teor de umidade das peças, durante o transporte e armazenagem, foi a principal razão para o aparecimento do problema dos fungos manchadores.

Definido os principais causadores dos problemas, a ferramenta $5 \mathrm{~W} 2 \mathrm{H}$ foi aplicada a fim de tomar as ações preventivas necessárias para controlar as causas potenciais, sendo que a função referente ao custo foi omitida por se tratar de informações confidenciais (Tabela 2).

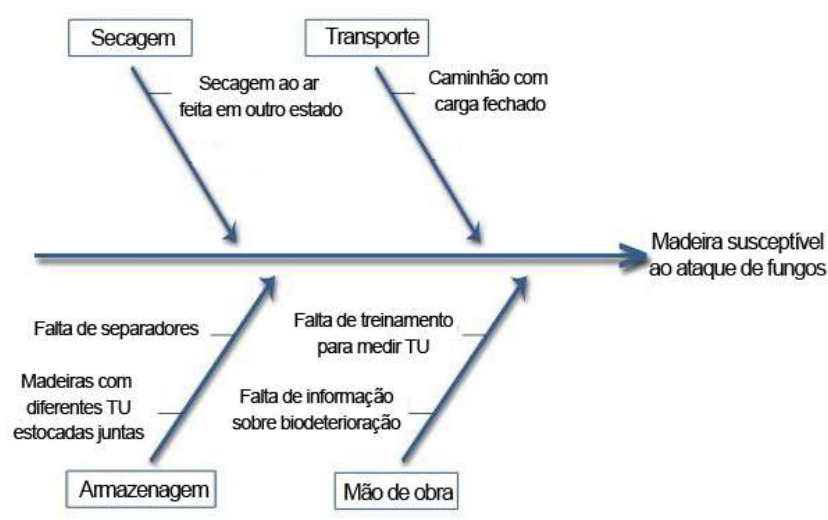

Figura 6. Aplicação do diagrama de Ishikawa para madeiras de Pinus susceptíveis ao ataque de fungos.

Figure 6. Ishikawa diagram applied for Pinus wood susceptible to fungal attack.

O plano abordou três linhas ações: as peças passarem a ser secas pelo método artificial; criar setores diferenciados nos locais de armazenamento; e qualificar os funcionários para identificar e solucionar problemas.

O ajuste do método de secagem realizado pelo fornecedor é necessário para que os teores de umidade das peças tornemse adequados para a realidade do local de comercialização. O transporte de peças secas abaixo da umidade de equilíbrio evitaria a propagação do fungo durante o percurso e a infestação generalizada. A adequação do método também seria refletida nos problemas de empenamento, responsáveis por $23 \%$ do total de defeitos, considerados como defeitos de secagem.

A segunda linha de ação independe da vontade de terceiros. O comércio local poderia minimizar o problema ao adotar um controle maior do seu produto armazenado. A separação das madeiras por classe de teor de umidade poderia auxiliar a execução de um período de secagem ao ar para adequar as condições das peças ao ambiente do uso final. Esta ação também evitaria a contaminação de tábuas saudáveis pelas já infectadas, uma vez que o início do ataque dos fungos manchadores ocorre no período de transporte da mercadoria.

Para que a ação de secagem das peças na madeireira fosse possível, a empresa teria que capacitar seus funcionários para os problemas relacionados ao teor de umidade e ataque de biodeterioração. Uma equipe consciente e com qualificação para identificar e tomar decisões de controle de qualidade poderia trabalhar em ações preventivas e corretivas para eliminar ou minimizar defeitos dos produtos.

\section{Conclusões}

Com base no estudo de caso realizado, as seguintes conclusões podem ser generalizadas para a qualidade das madeiras comercializadas em Mossoró;

A madeira de Pinus sp. apresentou maior quantidade de defeitos do que as madeiras de Manilkara sp.;

A nodosidade foi um defeito presente em todas as tábuas de Pinus, porém o conjunto de defeitos relacionados ao processo de secagem inadequado foi o mais frequente;

Os planos de ações propostos envolveram tanto, mudanças de comportamento do fornecedor, quanto ações internas da empresa para minimizar os defeitos. 
Tabela 2. Plano de ação 5W2H para madeiras de Pinus susceptíveis ao ataque de fungos.

Table 2. 5W2H action plan for Pinus wood susceptible to fungal attack.

\begin{tabular}{|c|c|c|c|c|c|}
\hline $\begin{array}{c}\text { O que fazer } \\
\text { (What })\end{array}$ & $\begin{array}{c}\text { Onde } \\
\text { (Where) }\end{array}$ & $\begin{array}{c}\text { Por quê } \\
(W h y)\end{array}$ & $\begin{array}{l}\text { Quando } \\
\text { (When) }\end{array}$ & $\begin{array}{l}\text { Quem } \\
\text { (Who) }\end{array}$ & $\begin{array}{l}\text { Como } \\
(\text { How })\end{array}$ \\
\hline Secagem artificial & $\begin{array}{c}\text { No local de } \\
\text { produção (PR) }\end{array}$ & $\begin{array}{l}\text { Para garantir um } \\
\text { TU abaixo da UE }\end{array}$ & $\begin{array}{l}\text { Antes do trans- } \\
\text { porte para o RN }\end{array}$ & Fornecedor & $\begin{array}{c}\text { Utilizar estufas } \\
\text { para secar a ma- } \\
\text { deira abaixo da } \\
\text { UE típica da re- } \\
\text { gião de comercia- } \\
\text { lização }\end{array}$ \\
\hline $\begin{array}{l}\text { Separar as peças de } \\
\text { acordo com o TU }\end{array}$ & $\begin{array}{l}\text { No pátio de } \\
\text { estoque da } \\
\text { empresa }\end{array}$ & $\begin{array}{l}\text { Para que peças } \\
\text { úmidas não afe- } \\
\text { tem o TU das pe- } \\
\text { ças já secas }\end{array}$ & $\begin{array}{c}\text { No recebimento } \\
\text { da madeira }\end{array}$ & $\begin{array}{l}\text { Equipe de fun- } \\
\text { cionários que } \\
\text { descarregam os } \\
\text { caminhões }\end{array}$ & $\begin{array}{c}\text { Criar diferentes } \\
\text { locais de estoca- } \\
\text { gem para classes } \\
\text { de umidade da } \\
\text { madeira. No caso } \\
\text { de madeiras } \\
\text { acima da UE, pro- } \\
\text { mover secagem ao } \\
\text { ar }\end{array}$ \\
\hline $\begin{array}{c}\text { Treinar funcionários } \\
\text { a identificar o pro- } \\
\text { blema }\end{array}$ & Na empresa & $\begin{array}{l}\text { Para que a equipe } \\
\text { saiba identificar } \\
\text { precocemente o } \\
\text { aparecimento de } \\
\text { infestações }\end{array}$ & $\begin{array}{l}\text { Durante todo o } \\
\text { período de ar- } \\
\text { mazenamento }\end{array}$ & Gerência & $\begin{array}{c}\text { Promover semi- } \\
\text { nários e cursos } \\
\text { sobre apareci- } \\
\text { mento de fungos e } \\
\text { medições de TU. }\end{array}$ \\
\hline
\end{tabular}

\section{Referências}

ASSOCIAÇÃO BRASILEIRA DA INDÚSTRIA DE MADEIRA PROCESSADA MECANICAMENTE - ABIMCI. Estudo setorial 2009, ano base 2008. Curitiba: ABIMCI, 2009. $43 \mathrm{p}$.

BENKO, R.; HIGHLEY, T. L. Selection of media for screening interaction of wood-attacking fungi and antagonistic bacteria II. Interaction on wood. Material und Organismen. v. 25, p. 173-180. 1990

BERGMAN, R. Drying and control of moisture content and dimensional changes. In: Forest Products Laboratory - FPL. Wood handbook - wood as an engineering material. FPLGTR-190. Madison: U.S. Department of Agriculture, Forest Service, Forest Products laboratory. p. 13.1 - 13.20, 2010.

BUSATTO, L. A.; TREVISAN, R.; MARTINS, N. L.; PILGER, A. H. Uso de secador solar para secagem de Pinus sp. Ciência da Madeira. v. 4, n. 2, p. 176-190, 2013.

CADEMARTORI, P. H. G.; GATTO, D. A.; STANGERLIN, D. M.; SCHNEID, E.; HAMM, L. G. Qualidade da madeira serrada de Pinus elliotti Engelm. procedente de florestas resinadas. Cerne. v. 18, n. 4, p. 577-583, 2012.
COLETTI, J.; BONDUELLE, G. M.; IWAKIRI, S. Avaliação de defeitos no processo de fabricação de lamelas para pisos de madeira engenheirados com uso de ferramentas de controle de qualidade. Acta Amazonica. v. 40, n. 1, p.135-140. 2010.

FOREST PRODUCTS LABORATORY - FPL. Air drying of lumber. FPL-GTR-117. Madison: U.S. Department of Agriculture, Forest Service, Forest Products laboratory. 62p. 1999.

GARTNER, B. L. Assessing wood characteristics and wood quality in intensively managed plantations. Journal of Forestry, v. 103, n. 2, p. 75-77, 2005.

GATTO, D. A.; SANTINI, E. J.; HASELEIN, C. R.; DURLO, M. A. Qualidade da madeira serrada na região da quarta colônia de imigração italiana do Rio Grande do Sul. Ciência Florestal. v. 14, n. 1, p.223-233. 2004.

HOADLEY, R. B. Understanding wood: a craftsman's guide to wood technology. Newtown: Taunton. 2000. 280p.

HUBBARD, S.; BOWE, S.; MACE, T.; KONING, J.; CARL$\mathrm{SON}, \mathrm{J}$. C. Blue stain, is it coloring your bottom line rede? Madison: DNR. 2005. 11p. 
INDÚSTRIA BRASILEIRA DE ÁRVORES - IBÁ. Relatório anual 2016. São Paulo: IBÁ, 2016. 96p.

INSTITUTO BRASILEIRO DE GEOGRAFIA E ESTATÍSTICA - IBGE. Pesquisa Anual da Indústria da Construção v. 24. Rio de Janeiro: IBGE, 2014. 50p.

JANKOWSKY, I. P. Variação sazonal da umidade de equilíbrio para madeira de Pinus. Scientia Forestalis. v. 31, p.4146. 1985.

KNAEBE, M. Blue stain. Techlines. v. 5, n.2, p. 1-2. 2002.

LENTINI, M. W.; GOMES, P. C.; SOBRAL, L. Acertando o alvo 3. Piracicaba: Imaflora, 2012. 73p.

LINS, B. F. E. Ferramentas básicas da qualidade. Ciência da informação. v. 22, n. 2, p.153-161. 1993.

SARAIVA, A. L. B. C.; VALE, C. C.; ZANELLA, M. E. Temperaturas na zona urbana e na zona rural no município de Mossoró-RN. Revista Geonorte, v. 2, n.5, p. 600-612. 2012

SERVIÇO FLORESTAL BRASILEIRO - SFB. A atividade madeireira na Amazônia brasileira: produção, receita e mercados. Belém: SFB, 2010. 20p.

SIMPSON, W. T. Dry kiln operator's manual. Madison: U.S. Department of Agriculture, Forest Service, Forest Products laboratory. 267p. 1991.

SILVA, L. F.; SILVA, M. L.; CORDEIRO, S. A. Análise do mercado mundial de madeiras tropicais. Revista de Política Agrícola, v. 21, n.3, p. 48-54. 2012.

SILVA, Z. A., G. P. G.; SOUSA, I. Z. G. Estrutura e conduta do mercado varejista de madeira serrada em Rio Branco Acre. Floresta, v. 40, n. 2, p. 355-371. 2010.

STANGERLIN, D. M.; SANTINI, E. J.; SUSIN, F.; MELO, R. R.; GATTO, D. A.; HASELEIN, C. R. Uso de estufa solar para secagem de madeira serrada. Ciência Florestal, v. 19, n. 4, p. 461-472. 2009. 